\title{
Intraperitoneal Chemotherapy in Patients Pretreated for Ovarian Cancer Matched with Patients Treated with Parenteral Chemotherapy
}

\author{
MARIA ORNELLA NICOLETTO ${ }^{1}$, ALESSANDRA CASARIN ${ }^{2}$, ALESSANDRA BALDONI ${ }^{1,3}$, \\ ELIANA RULLI ${ }^{4}$, GIULIA TASCA ${ }^{1,3}$, ZORA BARETTA $^{1}$, GRAZIA ARTIOLI ${ }^{5}$, GIUSEPPE LOMBARDI ${ }^{6}$, \\ ALESSANDRO CAPPETTA $^{5}$, IRENE FLORIANI ${ }^{4}$, GIOVANNI RANDON $^{2}$, SARA VALPIONE $^{1,3}$, \\ PIERO LITTA ${ }^{7}$, PIERFRANCO CONTE $^{1,2,3}$, SIMONE MOCELLIN $^{8}$ and CAMILLO ALIBERTI ${ }^{9}$ \\ ${ }^{1}$ Medical Oncology Unit 2, ${ }^{6}$ Medical Oncology Unit $1,{ }^{8}$ Oncological Surgery Unit and \\ ${ }^{9}$ Radiology Unit, Veneto Institute of Oncology - IRCCS, Padua, Italy; \\ ${ }^{2}$ Medical School, ${ }^{3}$ Department of Surgery, Oncology and Gastroenterology, \\ ${ }^{7}$ Department of Obstetrics and Gynecology, University of Padua, Padua, Italy; \\ ${ }^{4}$ Laboratory of Methodology for Clinical Research, Department of Oncology, \\ Mario Negri Pharmacological Research Institute, Milan, Italy; \\ ${ }^{5}$ Oncology and Hematology Unit, Mirano Hospital, Venice, Italy
}

\begin{abstract}
Background: Our aim was to analyze the impact of intraperitoneal chemotherapy (IPC), administered with direct peritoneal puncture, on the survival of patients with pretreated ovarian cancer in a real-life setting. Patients and Methods: This was a retrospective study comparing patients with advanced ovarian cancer treated with IPC $(N=33)$ and patients treated with standard intravenous (i.v.) chemotherapy matching cases for known prognostic factors (age, platinum sensitivity, histological subgroup and grade). Data were then analyzed for survival with nested Cox multivariate regression. Results: The case matching resulted in two homogeneous cohorts by age, platinum sensitivity, resistance to therapy and histology. When analyzed by hazard ratio (HR), the number of previous treatments and IPC vs. i.v. therapy were significant ( $H R=1.97$ for i.v. and $H R=1.90$ for each incremental previous treatment line, multivariate $p<0.001)$. When analyzing the patients with fewer than three previous treatment lines, IPC conferred a survival advantage of about 2.2 months (IPC $=10.0$ vs. i.v. $=7.8$ months, $p=0.011)$. However, the survival advantage in heavily pre-treated patients (with three or more previous treatments) was not significant. One case, pre-treated with more lines of chemotherapy, with renal failure after intraperitoneal cisplatin was followed by death. None of the patients had bowel sub-
\end{abstract}

Correspondence to: Ornella Nicoletto, via Gattamelata 64, Istituto Oncologico Veneto-IRCCS, Padua, Italy. Tel/Fax:+39 0498215931/32, e-mail: ornella.nicoletto@ioveneto.it

Key Words: Intraperitoneal treatment, parenteral chemotherapy, pretreated ovarian cancer. occlusions and we recorded a lower incidence of local toxicity, such as cellulite, with IPC (two out of 33 cases). Two patients thereafter refused IPC due to abdominal pain. Conclusion: Our findings confirm that IPC is an effective approach compared to systemic chemotherapy for advanced ovarian cancer, even in pre-treated patients, including platinum-resistant cases. The survival benefit appears to be confined to non-heavily treated patients. Overall, direct intraperitoneal drug injection (without permanent devices) appears to be feasible, safe and possibly advantageous.

Ovarian cancer is the eighth most common cancer among women, and is the fifth leading cause of cancer-related death among women, hence it is the deadliest of gynecological cancers. Mortality rates are slightly higher for Caucasian women than for African-American women (1). Most patients with advanced cancer have a $70 \%$ probability of recurrence and death because of disease progression. Therefore, more effective therapies are needed for this aggressive cancer, especially for pre-treated patients.

The peritoneum is the most frequent site of disease spread and treatment failure in the majority of advanced ovarian cancers (2). The treatment of ovarian cancer by intraperitoneal chemotherapy (IPC) was performed in several phase II trials with cisplatin/paclitaxel, showing the feasibility of the procedure and leading to an overall survival spanning from 8 months for patients with less than $2 \mathrm{~cm}$ residual disease to 43 months for patients with minimum residual disease (smaller than $0.5 \mathrm{~cm}$ ) (3-6). Moreover, when IPC was tested in patients with no residual mass greater than $1.0-2 \mathrm{~cm}$ after first surgery in phase III trials, it showed significant survival benefit 
compared to intravenous (i.v.) chemotherapy (7-10). However, since patients with minimal residual disease are the minority and this issue is still the object of debate, neoadjuvant i.v. chemotherapy followed by interval surgery is currently recommended (11), despite the results obtained with IPC. Moreover, another article by Markman et al. showed that IPC after neoadjuvant and interval surgery conferred an advantage of 5 months in overall survival and 9 months in progressionfree survival (12).

Concerns about local toxicity and permanent catheter complications or malfunctioning have led to a cautious introduction of the IPC procedure in European clinical practice (13-15). With the exception of trabectedin, which demonstrated an overall survival improvement of 6 months in partially sensitive patients, new therapies for advanced ovarian cancer in inoperable and relapsed disease, such as bevacizumab and poly ADP-ribose polymerase inhibitors have only improved disease-free survival, without consistent impact on overall survival (16-18). Of note, there are no data for direct intraperitoneal puncture applied in a non-drug-naïve setting, in particular for heavily pre-treated patients. The aim of the present study was to assess both efficacy and tolerability of IPC performed with direct puncture (as an alternative approach to permanent catheter) (19-20) for the treatment of previously treated patients with advanced ovarian cancer in a real-life setting.

\section{Patients and Methods}

Patients. Patients with advanced ovarian cancer (intraperitoneal disease or ascites) who received IPC between January 2006 and June 2015 (N=33) were retrospectively identified from the prospectively maintained database of our Institution. For each IPC case, the database was also queried to identify two patients who received i.v. chemotherapy $(\mathrm{N}=66)$ and matched IPC cases in terms of age, platinum sensitivity after first-line chemotherapy, histology, grade according to the International Federation of Gynecology and Obstetrics (FIGO) criteria and the World Health Organisation (WHO) system (22), year of first diagnosis as date of first surgery (medium interval of 12 months). We administered IPC as cisplatin on day 1 followed by paclitaxel on day 8 every 21-28 days for 3-4 cycles. Before they could receive a subsequent cycle of IPC, patients were required to have an absolute neutrophil count of 1,500 cells $/ \mathrm{mm}^{3}$ or greater, a platelet count of 100,000 cells $/ \mathrm{mm}^{3}$ or greater, and a creatinine level of $2.0 \mathrm{mg} / \mathrm{dl}$ or less. Treatment modifications for hematological toxic effects included cycle delay and dose reduction. Treatment was postponed in cases of creatinine level greater than $2.0 \mathrm{mg} / \mathrm{dl}(\mathrm{N}=1)$. Patients in whom treatment was delayed for more than three weeks were removed from IPC (39.4\%). Among patients in the IPC group, the dose of intraperitoneal drugs was reduced in the case of grade 2 abdominal pain and if these were persistent after dose reduction, they did not receive further IPC.

In the IPC arm, 14 patients had platinum-sensitive disease which became platinum resistant, and 12 had platinum-sensitive and seven platinum-resistant disease from the outset. Clinical response was considered the disappearance of ascites or stabilization of the ascites for over 45 days.
The survival observation starting point was the date of first IPC administration versus the date of the first corresponding i.v. treatment in the matched cases (i.e. if the patient received IPC as third line of treatment, the observation start for survival comparison was the date of the third i.v. therapy regimen for the two matched i.v. cases).

Treatment. The infusion used a set comprising a Veress needle (15 gauge, $100 \mathrm{~mm}$ ), a bag with drain-tap and a 3-way stopcock $360^{\circ}$. The interventional radiologist inserted the Veress needle in the peritoneum smiled by ultrasound scan. The ascites, if present, was drained and collected within the bag. The patients were then transferred to the Medical Oncology Department for peritoneal drainage and IPC.

An infusion bag of 500-1000 cc of 0.9\% saline solution was heated to a temperature between 30 and $35^{\circ} \mathrm{C}$ using a waterbath Argolab WB 12 (Corato SAS, Verona, Italy) and was connected to the 3-way stopcock. The stopcock was opened and the saline solution was infused in 30 minutes to prepare the peritoneum to receive the treatment. At the end of the saline infusion, the bag containing the drug was connected to the 3-way stopcock and infused as fast as possible.

The procedure was performed with local anesthesia $(5 \mathrm{ml}$ of bupivacaine or lidocaine diluted with $5 \mathrm{ml}$ of $0.9 \%$ saline solution) and monitoring of vital signs. On the first day of the cycle, cisplatin was administered at a fixed dosage of $100 \mathrm{mg}$ for pre-treated patients. The drug was diluted in $500 \mathrm{cc}$ of $0.9 \%$ saline solution and infused into the peritoneum as rapidly as possible. Parenteral i.v. was infused in 2 litres of glucose solution with normal saline with $3 \mathrm{~g}$ of magnesium sulfate and $40 \mathrm{~g}$ of mannitol (7), with premedication with corticosteroids and antiemetic, according to standard institutional procedures (7-9). We added hydration on the days following IPC to avoid nephrotoxicity. In the case of mild renal impairment, we administered carboplatin (22) at a fixed dosage of 4 areas under the curve (AUC) for pre-treated patients.

The second part of the cycle was administered after 7 days. This consisted of the administration of IPC paclitaxel at a fixed dose of $90 \mathrm{mg}$ in $250 \mathrm{cc}$ of $0.9 \%$ saline solution, due for pre-treatment.

At the end of IPC infusion, a further peritoneal washing with $500 \mathrm{cc}$ of $0.9 \%$ saline solution was administered (7-9). The Veress needle was removed at the end of the procedure and compressive medication was applied. In the days after treatment, creatinine, ionemia and vital signs were monitored daily for 1 week.

Intravenous chemotherapy was by clinician's choice, according to international guidelines (23-25), and in the case of allergy to taxol or platin salts, premedication was required according to Castells and Reeves $(26,27)$.

Adverse events were recorded according to Common Toxicity Criteria for Adverse Events (CTCAE) v. 4.03. (28).

Statistical analyses. The power of the study was not pre-planned as the aim of the project was exploratory and descriptive. There was no selection of patients outside the inclusion and matching criteria. Patients were eventually grouped according to the number of previous chemotherapy lines, by grouping criterion of fewer than three and three or more lines. Data analysis was performed by means of nested Cox regression, interaction was designed for investigational treatment (IPC vs. i.v.) and number of previous therapy lines. Wald test with analysis of variance was used after the building of the regression model, the proportional hazard assumption was verified by means of Schoenfeld residuals. Observation time started from the date of the corresponding line of i.v. chemotherapy. Survival was estimated with the KaplanMeier method, and differences in the studied cohorts were calculated 
Table I. Comparison of complication reports.

\begin{tabular}{lcccc}
\hline & Author (Ref) & No. of patients & Catheter dysfunction & Infection \\
\hline Peritoneal catheter & Walker et al. (15) & 189 & $26.4 \%$ & $13.2 \%$ \\
& Sakuragi et al. (13) & 78 & $6.4 \%$ & $20.5 \%$ \\
& Landrum et al. (14) & 83 & $6 \%$ & $4.8 \%$ \\
Direct puncture of abdomen & Lan et al. (19) & 194 & $1 \%$ & 0 \\
& Benedetti-Panici et al. (20) & 38 & $1.5 \%$ & 0 \\
\hline
\end{tabular}

Table II. Characteristics of patients according to intraperitoneal (IPC) and intravenous (IV) therapy.

\begin{tabular}{|c|c|c|c|c|}
\hline Variable & IPC, n (\%) & $\mathrm{IV}, \mathrm{n}(\%)$ & HR & $p$-Value \\
\hline Median age (years) & 62.6 & 667 & 1.0 & 0.332 \\
\hline Platinum-sensitivity & $25(75.7 \%)$ & $50(75.7 \%)$ & 1 & 0.003 \\
\hline Platinum-resistance & $7(21.2 \%)$ & $14(21.2 \%)$ & 1.8 & \\
\hline Platinum-refractory & $1(3 \%)$ & $2(3 \%)$ & 8.9 & \\
\hline \multicolumn{5}{|l|}{ Histological grade } \\
\hline 2 & $2(6.1 \%)$ & $6(9.1 \%)$ & 1 & 0.976 \\
\hline $3-4$ & $31(93.1)$ & $60(90.9 \%)$ & 1.1 & \\
\hline \multicolumn{5}{|l|}{ Histology } \\
\hline Undifferentiated & $5(15,1 \%)$ & $11(16.7 \%)$ & 1 & 0.275 \\
\hline Clear cell & $1(3 \%)$ & $2(3 \%)$ & 3.7 & \\
\hline Other epithelial subtype & $6(18,2 \%)$ & $9(13.6 \%)$ & 10.0 & \\
\hline Serous & $21(63,6 \%)$ & $44(66.7 \%)$ & 2.7 & \\
\hline Median no. of previous treatments & 3 & 2 & $1.9^{*}$ & $<0.001$ \\
\hline \multicolumn{5}{|l|}{ Administration route } \\
\hline IPC & $33(100 \%)$ & 0 & 1 & 0.010 \\
\hline IV & 0 & $66(100 \%)$ & 1.97 & \\
\hline
\end{tabular}

HR: Hazard ratio. *For each incremental treatment.

with log-rank test. Comparison of variables was performed by means of Chi-square, Fisher or Wilcoxon-Mann-Whitney test according to the nature and numerosity of the variable. Two-sided $p$-values are reported. Statistical analyses were performed with R 3.2.2 (survival and rms libraries; R Foundation for Statistical Computing, Vienna, Austria).

Patients gave consent to use their data for scientific purposes, and the study was performed under local Ethic Committee approval (number 15/2015).

\section{Results}

The case-by-case matching resulted in two homogeneous cohorts, IPC vs. i.v.: by age group (62 vs. 65 years), platinum sensitive [25 $(75.8 \%) v s .50(75.8 \%)]$, resistant [7 (21.2\%) vs. $14(21.2 \%)$ ], refractory [1 (3\%) vs. $2(3 \%)$, histology [serous: 21 patients $(63.6 \%)$ vs. 44 (66.7\%); undifferentiated: $5(15.1 \%)$ vs. 11 (16.7\%); epithelial-mixed: $6(18.2 \%)$ vs. 9 (13.6\%); clear cell: $1(3 \%)$ vs. $2(3 \%)$ ], histological grade [grade 2: $2(6 \%) v s$. $6(9 \%)$; grade 3-4: $31(93.1 \%)$ vs. $60(90.9 \%)]$.

The treatment was well tolerated. The main adverse event observed was in patient with severe ascites and seven lines of prior chemotherapy; the patient developed progressive renal failure after first intraperitoneal cisplatin, deteriorating until death, occurred on day 8.Three patients stopped IPC because of pain (two after second cycle, responsive to treatment, and one after the third cycle, without response to treatment) consequent to grade 2 cellulite (caused by the shift of the needle in two cases, as a result of abrupt needle dislocation during the transfer from stretcher to bed, and which resolved spontaneously). Table I provides a comparison of adverse events observed with IPC in published series and in our cohort.

Table II summarizes patient characteristics according to treatment group, and the impact of these features on the hazard of death. At Cox regression analysis, histology, grade and age did not impact on the hazard of death, while platinum sensitivity status $(\mathrm{HR}=1.8$ and $\mathrm{HR}=8.9$ for platinum resistance and refractoriness, respectively; $p=0.003$ ) and administrative route $(\mathrm{HR}=1.97$ for $i . v ., p=0.010)$ ignificant. In addition, the number of previous treatments had an impact on the hazard of death $(\mathrm{HR}=1.9$ for each incremental line, $p<0.0001)$. After Wald analysis, only administrative route $(p=0.007)$ and the number of previous treatments $(p<0.001)$ maintained significance. We then repeated the analysis selecting covariates that were 
Table III. Survival in intraperitoneal (IPC) and intravenous (IV) therapy groups according to pretreatment.

\begin{tabular}{|c|c|c|c|c|c|}
\hline \multirow[t]{2}{*}{ Group } & \multirow[t]{2}{*}{ Study treatment } & \multirow[t]{2}{*}{$\mathrm{N}$} & \multicolumn{2}{|c|}{ Deaths, n $(\%)$} & \multirow{2}{*}{ Overall survival } \\
\hline & & & & At 1 year $(\%)$ & \\
\hline \multirow{2}{*}{ Not-heavily pre-treated ( $<2$ previous lines) } & IPC & 16 & $13(81 \%)$ & 48.1 & 10.0 \\
\hline & IV & 45 & $40(88.8 \%)$ & 40.2 & 7.8 \\
\hline \multirow[t]{2}{*}{ Heavily pre-treated ( $3 \geq$ previous lines) } & IPC & 17 & $16(94 \%)$ & 36.4 & 4.4 \\
\hline & IV & 21 & $21(100 \%)$ & 10.6 & 4.2 \\
\hline
\end{tabular}

significant (platinum sensitivity at the beginning of the disease, number of previous treatments and treatment with IPC or i.v. chemotherapy) and hypothesized an interaction between the route of administration and number of previous treatments. IPC treatment had a positive impact on the hazard of death only in the subgroup of not heavily pre-treated patients $[\mathrm{HR}=0.21,95 \%$ confidence interval $(\mathrm{CI})=0.09-0.48, p<0.001]$, while in patients who had previously received three or more treatment lines, the benefit was unimportant $(\mathrm{HR}=0.55,95 \% \mathrm{CI}=0.27-1.12$, $p=0.101)$. When analyzing the patients with fewer than three previous treatment lines, IPC had a survival advantage of 2.2 months (IPC $=10.0$ vs. i.v. $=7.8$ months, $p=0.011$ ). The prognostic advantage in heavily pretreated patients (with three or more previous treatments) was not significant. The significant impact of platinum sensitivity status on prognosis was confirmed, as patients with refractory and platinumresistant disease had an $\mathrm{HR}$ of 5.7 (95\% CI=1.62-20.14, $p=0.038)$ and $1.8(95 \% \mathrm{CI}=1.03-3.16, p=0.006)$, respectively.

Four $(12.1 \%)$ patients in the IPC arm were alive after a median follow-up of 22 months and five (7.57\%) patients were alive in the i.v. group after a median follow-up of 16 months. Table III summarizes the survival data for the two treatment cohorts according to pretreatment group, and Figure 1 reports the survival curve for IPC and i.v. cohorts for notheavily pretreated patients.

Within the IPC group, 27 patients had ascites, and six patients had peritoneal carcinomatosis only. Fourteen $(51.8 \%)$ out of 27 patients had a clinical response, with disappearance or significant reduction of ascites for more than 45 days after IPC. Information on ascites was not available in the i.v. group.

The cost of standard intravenous regimens for advanced ovarian cancer, including bevacizumab, pegylated liposomal doxorubicin plus oxliplatin and pegylated liposomal doxorubicin plus trabectedin, catumaxomab and IPC are compared in Table IV. As may be seen, the expense savings are of the order of up to 12 times in favor of $\operatorname{IPC}(16,18,29)$.

\section{Discussion}

The efficacy of first-line IPC with cisplatin/paclitaxel in ovarian epithelial cancer is well documented in phase III studies $(7-9,30,31)$. Of note, striking survival data have been recorded for patients with responsive disease, with a consistent number of patients alive after 120 months in this group (31). As consequence, the toxicities, issues and cost of IPC appears justified from the survival benefit. This retrospective case-matched report endorses a significant role in previously treated patients, such as in second and third line (i.e. for patients with fewer than three previous therapy lines), partly confirming the experience of Markman and colleagues about intraperitoneal treatment after neoadjuvant chemotherapy and interval surgery (12).

Pre-treated patients represent the majority of the ovarian cancer population; moreover, they are often candidates for palliative treatment only and excluded from clinical trials with new drugs. Therefore, studies for effective and possibly not expensive second and third line treatments can be considered a priority for patients despite age and platinum sensitivity. Intraperitoneal catumaxomab, a monoclonal antibody designed to reduce ascites production in patients with cancer, can prolong the interval between peritoneal drainage, but a clinical objective response was not reported (32). On the contrary, more than half of the patients in the IPC group in our study experienced significant improvement of ascites and, of consequence, a reduction of the need for ascites drainage, with intervals of longer than 45 days.

According to our results, IPC was well-tolerated. In particular, direct intraperitoneal puncture, avoiding permanent catheterization, was associated with minor toxicities when compared with historical series of IPC administrated by permanent catheter, confirming the reports of Lan et al. (19) and Benedetti-Panici et al. (20) in a first-line setting. In particular, we recorded one possible toxic death but the clinical impression was of multi-organ failure, in the context of heavily pretreated disease not responding to last-resort therapy. No bowel obstructions and infections (considering cellulite an inflammatory adverse event) with IPC were registered, as opposed to other studies that used permanent devices (7-9). As confirmation of the tolerability and feasibility of IPC, the procedure was safe, even in elderly pretreated patients. As confirmation of the procedure's safety and feasibility, there is a report of IPC administered during pregnancy. In fact, a primiparous woman received four cycles 


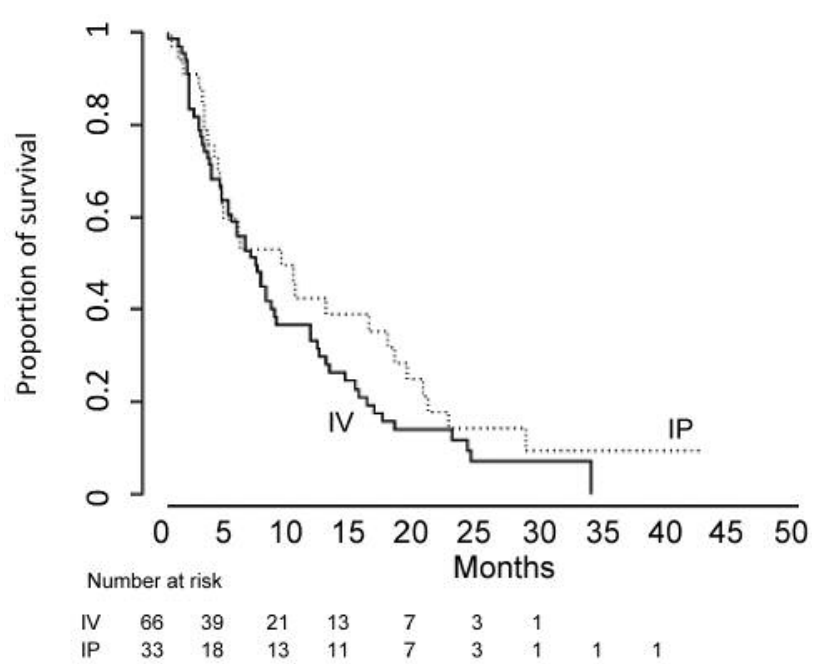

Figure 1. Overall survival curve for patients treated with intraperitoneal (IP) or intravenous (IV) chemotherapy.

Table IV. Costs of intraperitoneal (IPC) and intravenous (IV) therapy.

\begin{tabular}{lcc}
\hline Chemotherapy regimen (Ref) & $\begin{array}{c}\text { One cycle } \\
(€)\end{array}$ & $\begin{array}{c}\text { Six cycles } \\
(€)\end{array}$ \\
\hline Trabectedin-pegylated doxorubicin (18) & 3,956 & 23,739 \\
Pegylated doxorubicin-oxaliplatin (32) & 639 & 3,838 \\
Carboplatin-gemcitabine-bevacizumab (17) & 3,284 & 19,767 \\
Catumaxomab & 1,225 & 7,350 \\
Cisplatin-paclitaxel IPC & 309 & 1,858 \\
\hline
\end{tabular}

of IPC from about the 14th gestational week (33), followed by successful caesarean delivery in the 37 th week.

Moreover, according to our results, IPC was associated with a survival advantage when compared with standard i.v. chemotherapy in unselected patients, even if the advantage was only significant for not heavily pretreated patients. Of note, the influence of platinum sensitivity still appears important as an independent prognostic factor, even if not discriminatory for the benefit from IPC.

In order to avoid needle dislocations and its consequences, as demonstrated by our experience, the positioning of the peritoneal needle should occur under ultrasound guidance directly at the patient's bed.

One of the disadvantages of IPC, it could be argued, would be the necessity for referral to a specialized center. However, multidisciplinary approaches and effective networks between peripheral and referral centers are already a priority of ovarian cancer patient management in modern oncology.

In conclusion, the issue of costs for expensive new cancer drugs that can offer limited advantage of overall survival is a topic of current debate. We confirm a benefit in terms of overall survival and costs for IPC and would foster further studies to improve feasibility and toxicity management to encourage the implementation in daily practice of this treatment approach for not-heavily pre-treated patients.

\section{References}

1 Urban RR, He H, Alfonso R, Hardesty MM, Gray HJ and Goff BA: Ovarian cancer outcomes: Predictors of early death. Gynecol Oncol 140(3): 474-480, 2016.

2 Ushijima K: Treatment for recurrent ovarian cancer-at first relapse. J Oncol 2010: 497429, 2010.

3 Howell SB, Zimm S, Markman M, Abramson IS, Cleary S, Lucas WE and Weiss RJ: Long-term survival of advanced refractory ovarian carcinoma patients with small-volume disease treated with intraperitoneal chemotherapy. J Clin Oncol 5: 1607-1612, 1987.

4 Markman M, Brady M, Hutson A and Berek JS: Survival after second-line intraperitoneal therapy for the treatment of epithelial ovarian cancer: the Gynecologic Oncology Group experience. Int J Gynecol Cancer 19: 223-229, 2009.

5 Speyer JL, Beller U, Colombo N, Sorich J, Wernz JC, Hochster $\mathrm{H}$, Green M, Porges R, Muggia FM, Canetta $\mathrm{R}$ et al: Intraperitoneal carboplatin: favorable results in women with minimal residual ovarian cancer after cisplatin therapy. J Clin Oncol 8: 1335-1341, 1990.

6 Nicoletto MO, Dalla Palma M, Donach ME, Gusella M, Cappetta A, Shams M, Marchet A, Nardin M, Pintacuda G, Di Maggio A, Marchesi M, Carli P, Fiduccia P, Artioli G and Nitti D: Positive experience of intraperitoneal chemotherapy followed by intravenous chemotherapy in heavily pretreated patients with suboptimal residual ovarian cancer and primary peritoneal cancer. Tumori 96: 918-925, 2010.

7 Alberts DS, Liu PY, Hannigan EV, O'Toole R, Williams SD, Young JA, Franklin EW, Clarke-Pearson DL, Malviya VK and DuBeshter B: Intraperitoneal cisplatin plus intravenous cyclophosphamide versus intravenous cisplatin plus intravenous cyclophosphamide for stage III ovarian cancer. N Engl J Med 335: 1950-1955, 1996.

8 Markman M, Bundy BN, Alberts DS, Fowler JM, Clark-Pearson DL, Carson LF, Wadler S and Sickel J: Phase III trial of standarddose intravenous cisplatin plus paclitaxel versus moderately highdose carboplatin followed by intravenous paclitaxel and intraperitoneal cisplatin in small-volume stage III ovarian carcinoma: an intergroup study of the Gynecologic Oncology Group, Southwestern Oncology Group, and Eastern Cooperative Oncology Group. J Clin Oncol 19: 1001-1007, 2001.

9 Armstrong DK, Bundy B, Wenzel L, Huang HQ, Baergen R, Lele S, Copeland LJ, Walker JL, Burger RA and Gynecologic Oncology G: Intraperitoneal cisplatin and paclitaxel in ovarian cancer. N Engl J Med 354: 34-43, 2006.

10 Lesnock JL, Darcy KM, Tian C, Deloia JA, Thrall MM, Zahn C, Armstrong DK, Birrer MJ and Krivak TC: BRCA1 expression and improved survival in ovarian cancer patients treated with intraperitoneal cisplatin and paclitaxel: a Gynecologic Oncology Group Study. Br J Cancer 108: 1231-1237, 2013.

11 Vergote I, Trope CG, Amant F, Kristensen GB, Ehlen T, Johnson $\mathrm{N}$, Verheijen RH, van der Burg ME, Lacave AJ, Panici PB, Kenter GG, Casado A, Mendiola C, Coens C, Verleye L, Stuart GC, 
Pecorelli S, Reed NS, European Organization for R, Treatment of Cancer-Gynaecological Cancer G and Group NCT: Neoadjuvant chemotherapy or primary surgery in stage IIIC or IV ovarian cancer. N Engl J Med 363: 943-953, 2010.

12 Tiersten AD, Liu PY, Smith HO, Wilczynski SP, Robinson WR, 3rd, Markman $M$ and Alberts DS: Phase II evaluation of neoadjuvant chemotherapy and debulking followed by intraperitoneal chemotherapy in women with stage III and IV epithelial ovarian, fallopian tube or primary peritoneal cancer: Southwest Oncology Group Study S0009. Gynecol Oncol 112: 444-449, 2009.

13 Sakuragi N, Nakajima A, Nomura E, Noro N, Yamada H, Yamamoto $\mathrm{R}$ and Fujimoto $\mathrm{S}$ : Complications relating to intraperitoneal administration of cisplatin or carboplatin for ovarian carcinoma. Gynecol Oncol 79: 420-423, 2000.

14 Landrum LM, Gold MA, Moore KN, Myers TK, McMeekin DS and Walker JL: Intraperitoneal chemotherapy for patients with advanced epithelial ovarian cancer: a review of complications and completion rates. Gynecol Oncol 108: 342-347, 2008.

15 Walker JL, Armstrong DK, Huang HQ, Fowler J, Webster K, Burger RA and Clarke-Pearson D: Intraperitoneal catheter outcomes in a phase III trial of intravenous versus intraperitoneal chemotherapy in optimal stage III ovarian and primary peritoneal cancer: a Gynecologic Oncology Group Study. Gynecol Oncol 100: 27-32, 2006.

16 Aghajanian C, Blank SV, Goff BA, Judson PL, Teneriello MG, Husain A, Sovak MA, Yi J and Nycum LR: OCEANS: a randomized, double-blind, placebo-controlled phase III trial of chemotherapy with or without bevacizumab in patients with platinum-sensitive recurrent epithelial ovarian, primary peritoneal, or fallopian tube cancer. J Clin Oncol 30: 2039-2045, 2012.

17 Audeh MW, Carmichael J, Penson RT, Friedlander M, Powell B, Bell-McGuinn KM, Scott C, Weitzel JN, Oaknin A, Loman N, Lu $\mathrm{K}$, Schmutzler RK, Matulonis U, Wickens M and Tutt A: Oral poly(ADP-ribose) polymerase inhibitor olaparib in patients with BRCA1 or BRCA2 mutations and recurrent ovarian cancer: a proof-of-concept trial. Lancet 376: 245-251, 2010.

18 Poveda A, Vergote I, Tjulandin S, Kong B, Roy M, Chan S, Filipczyk-Cisarz E, Hagberg H, Kaye SB, Colombo N, Lebedinsky C, Parekh T, Gomez J, Park YC, Alfaro V and Monk BJ: Trabectedin plus pegylated liposomal doxorubicin in relapsed ovarian cancer: outcomes in the partially platinum-sensitive (platinum-free interval 6-12 months) subpopulation of OVA-301 phase III randomized trial. Ann Oncol 22: 39-48, 2011.

19 Lan C, Li Y and Liu J: Intraperitoneal access via direct puncture is an alternative way to deliver intraperitoneal chemotherapy in ovarian, fallopian tube and primary peritoneal cancer. Gynecol Oncol 114: 42-47, 2009.

20 Benedetti-Panici P, Perniola G, Marchetti C, Pernice M, Donfrancesco C, Di Donato V, Tomao F, Palaia I, Graziano M, Basile $\mathrm{S}$ and Bellati F: Intraperitoneal chemotherapy by ultrasoundguided direct puncture in recurrent ovarian cancer: feasibility, compliance, and complications. Int J Gynecol Cancer 22: 10691074, 2012.

21 Scully RE: World Health Organization classification and nomenclature of ovarian cancer. Natl Cancer Inst Monogr 42: 57,1975 .

22 Fujiwara K, Markman M, Morgan $M$ and Coleman RL: Intraperitoneal carboplatin-based chemotherapy for epithelial ovarian cancer. Gynecol Oncol 97: 10-15, 2005.
23 Morgan RJ, Jr., Alvarez RD, Armstrong DK, Boston B, Burger RA, Chen LM, Copeland L, Crispens MA, Gershenson D, Gray HJ, Grigsby PW, Hakam A, Havrilesky LJ, Johnston C, Lele S, Matulonis UA, O'Malley DM, Penson RT, Remmenga SW, Sabbatini P, Schilder RJ, Schink JC, Teng N, Werner TL and National Comprehensive Cancer N: Epithelial ovarian cancer. J Natl Compr Canc Netw 9: 82-113, 2011.

24 Morgan RJ Jr., Alvarez RD, Armstrong DK, Burger RA, Castells M, Chen LM, Copeland L, Crispens MA, Gershenson D, Gray H, Hakam A, Havrilesky LJ, Johnston C, Lele S, Martin L, Matulonis UA, O’Malley DM, Penson RT, Remmenga SW, Sabbatini P, Santoso JT, Schilder RJ, Schink J, Teng N, Werner TL, Hughes M, Dwyer MA and National Comprehensive Cancer N: Ovarian cancer, version 3.2012. J Natl Compr Canc Netw 10: 1339-1349, 2012.

25 Morgan RJ, Jr., Alvarez RD, Armstrong DK, Burger RA, Chen LM, Copeland L, Crispens MA, Gershenson DM, Gray HJ, Hakam A, Havrilesky LJ, Johnston C, Lele S, Martin L, Matulonis UA, O'Malley DM, Penson RT, Powell MA, Remmenga SW, Sabbatini P, Santoso JT, Schink JC, Teng N, Werner TL, Dwyer MA, Hughes $\mathrm{M}$ and National comprehensive cancer n: Ovarian cancer, version 2.2013. J Natl Compr Canc Netw 11: 1199-1209, 2013.

26 Picard M and Castells MC: Re-visiting hypersensitivity reactions to taxanes: a comprehensive review. Clin Rev Allergy Immunol 49: 177-191, 2015.

27 Reeves DJ, Callahan MJ and Sutton GP: Successful desensitization to docetaxel after severe hypersensitivity reactions in two patients. Am J Health Syst Pharm 69: 499-503, 2012.

28 U.S. Department of Health and Human Services, National Institutes of Health - National Cancer Institute. Common Terminology Criteria for Adverse Events (CTCAE). Version 4.0. Published: May 28, 2009 (v4.03: June 14, 2010).

29 Nicoletto MO, Bertorelle R, Borgato L, De Salvo GL, Artioli G, Lombardi G, Zustovich F, Marcato R, Parenti A, Montagna M and Donach ME: Family history of cancer rather than p53 status predicts efficacy of pegylated liposomal doxorubicin and oxaliplatin in relapsed ovarian cancer. Int J Gynecol Cancer 19: 1022-1028, 2009.

30 Wright AA, Cronin A, Milne DE, Bookman MA, Burger RA, Cohn DE, Cristea MC, Griggs JJ, Keating NL, Levenback CF, Mantia-Smaldone G, Matulonis UA, Meyer LA, Niland JC, Weeks JC and O'Malley DM: Use and effectiveness of intraperitoneal chemotherapy for treatment of ovarian cancer. $\mathrm{J}$ Clin Oncol 33: 2841-2847, 2015.

31 Tewari D, Java JJ, Salani R, Armstrong DK, Markman M, Herzog T, Monk BJ and Chan JK: Long-term survival advantage and prognostic factors associated with intraperitoneal chemotherapy treatment in advanced ovarian cancer: a Gynecologic Oncology Group study. J Clin Oncol 33: 1460-1466, 2015.

32 Strohlein MA and Heiss MM: The trifunctional antibody catumaxomab in treatment of malignant ascites and peritoneal carcinomatosis. Future Oncol 6: 1387-1394, 2010.

33 Smith ER, Borowsky ME and Jain VD: Intraperitoneal chemotherapy in a pregnant woman with ovarian cancer. Obstet Gynecol 122: 481-483, 2013.

Received August 8, 2016

Revised September 27, 2016

Accepted September 29, 2016 